\title{
Implementing an innovative intervention to increase research capacity for enhancing early psychosis care in Indonesia
}

\author{
Laoise Renwick, RMN, BNS, PhD, FHEA ${ }^{1 *}$ \\ Irmansyah, $\mathrm{MD}, \mathrm{PhD}^{2}$ \\ Budi Anna Keliat, RMN, BNS, $\mathrm{PhD}^{3}$ \\ Karina Lovell, RMN, BA, MSc, $\mathrm{PhD}^{1}$
}

\begin{abstract}
Alison Yung, MD MBBS MPM FRANZCP Grad Dip Epidem ${ }^{4}$
${ }^{1}$ Division of Nursing, Midwifery \& Social Work, School of Health Sciences, University of Manchester, UK

${ }^{2}$ Marzoeki Mahdi Hospital, Bogor, Indonesia

${ }^{3}$ Faculty of Nursing, Universitas Indonesia, Depok, Indonesia

${ }^{4}$ Division of Psychology and Mental Health, School of Health Sciences, University of Manchester, UK

* correspondence

Dr. Laoise Renwick | Lecturer, Division of Nursing, Midwifery and Social Work, School of Health Sciences, Faculty of Biology, Medicine and Health | University of Manchester | Manchester Academic Health Science Centre
\end{abstract}

Room 6.304 Jean McFarlane Building | Oxford Road | Manchester M13 9PL | Tel: +44 (0)161 3067833

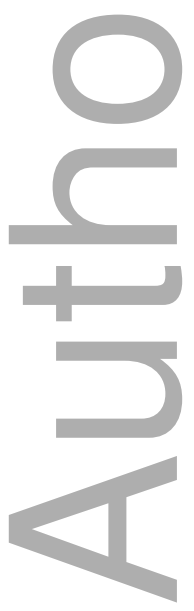

This is the author manuscript accepted for publication and has undergone full peer review but has not been through the copyediting, typesetting, pagination and proofreading process, which may lead to differences between this version and the Version of Record. Please cite this article as doi: $10.1111 /$ ipm.12417

This article is protected by copyright. All rights reserved 


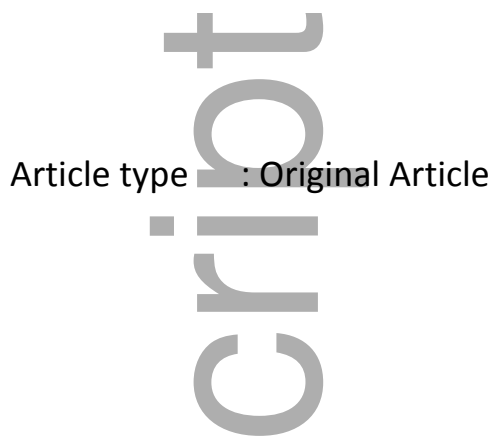

Corresponding author mail id: laoiserenwick@gmail.com

\section{Abstract}

Keywords: early psychosis, global health, non-communicable diseases, research capacity building

Aim

To strengthen research capacity for nurses and early career researchers in Indonesia and the UK to develop a local evidence base in Indonesia to inform policy and improve the nation's health. These strategies can strengthen research institutions, enhance trial capacity, improve quality standards and improve attitudes towards the importance of health research.

Methods

Four days of workshops were held in Jakarta, Indonesia developing collaborative groups of academic nurses and early career researchers from the UK and Indonesia (30 people including mentors) to produce competitive grant bids to evaluate aspects of early psychosis care. Qualitative and quantitative evaluations were conducted.

Results

Participants evaluated the workshops positively finding benefit in the structure, content and delivery. Research impact was shown by attaining several successful small and large grants and developing offshoot collaborative relationships.

Discussion

These novel findings demonstrate that collaborative workshops can strengthen research capacity by developing partnerships and instigating new collaborations and networks. No other studies of international research partnerships among mental health nurses have reported this outcome to our knowledge.

Implications for Practice

This method could be implemented to improve networking and collaboration between UK academics and early career researchers and also with external colleagues in other LMICs.

\section{Relevance}

This manuscript describes the conduct and evaluation of workshops to enhance research capacity among nurses in the UK and Indonesia to benefit evidence-based care and treatment for people with first-episode psychosis. 
As such this manuscript has direct relevance to the development of mental health nursing in low-resource settings due to role expansion and enhanced competencies but also relevant to nursing care in the UK context in view of the changing political landscape of nursing and psychosis care.

\section{Accessible Summary}

\section{What is known on the topic?}

- In low and middle-income settings (LMICs) such as Indonesia, the burden from psychotic illness is significant due to large gaps in treatment provision

- Mental health workers and community nurses are a growing workforce requiring new evidence to support practice and enhanced roles and advanced competencies among UK mental health nurses also requires greater research capacity

- Research capacity building projects can strengthen research institutions, enhance trial capacity, improve quality standards and improve attitudes towards the importance of health research.

\section{What this paper adds}

- Delivering innovative, cross-cultural workshops to enhance research capacity to multi-disciplinary, early career researchers in Indonesia and the UK are rated highly by attendees

- Supporting people in this way helps them to gain competitive grant funding to complete their own research which can improve the health of the population

- To our knowledge, there are no other studies reporting the attainment of grant income as a successful outcome of international research partnerships for mental health nursing so our finding is novel

\section{What are the implications for practice?}

- This method could be implemented to improve networking and collaboration between UK academics and early career researchers in other lower and middle-income settings

- This strategy can also strengthen existing partnerships among early career researchers in the UK to meet the demands for greater research mentorship and leadership among mental health nurses and enhance nurses capabilities to contribute to evidence for practice

\section{Introduction}

In Indonesia, a shortage of trained personnel and leadership among mental health nurses has impeded progress towards basic care provision such that meeting the healthcare needs of this population is a major challenge (Barber and Gertler, 2008). Indeed, Indonesia has the lowest rate of skilled mental health workers of all the Asian nations and the professionalisation of mental health nursing is in its infancy. To improve health outcomes 
in low and middle income settings (LMICs), strengthening research capacity is a powerful, cost-effective and sustainable way to achieve this goal (Evans 1990). Research capacity building strategies can strengthen research institutions, enhance trial capacity, improve quality standards and improve attitudes towards the importance of health research (Franzen et al., 2017).

Documented in early reports, Indonesia has the highest rate of disability from schizophrenia (DALYs) of any country in the world (Ayuso-Mateos, 2000). In the World Health Organisation Global Burden of Diseases Study 2010, schizophrenia continued to be a leading cause of disability-adjusted life years in South Asia (Murray et al., 2012). There is limited access to mental health services, poor levels of awareness, stigma and a largely untrained workforce. The disability caused by schizophrenia in Indonesia is quite substantial and is well documented in the media following the publication of the 2016 World Report (Human Rights Watch, 2016). While journalistic reports are not as rigorous as scientific studies these reports provide a clear depiction of the disability and human rights violations suffered by people with schizophrenia (Jones, 2016). Similarly, studies of the epidemiology of disease show almost 60,000 people are committed to pasung and are shackled, often in wooden blocks or kept in cages severely restricting their freedom (Idaiani et al., 2014).

We promoted UK: Indonesia collaboration among early career researchers comprising nurses, doctors and allied health professionals with the aim of enhancing research capacity to develop potentially fundable research projects based on research priorities in Indonesia being mindful of socio-cultural factors such as local wisdom, beliefs, customs and practices. As our interest was primarily to strengthen care provision for people with serious mental illness and schizophrenia, we developed our collaboration through a shared vision of improving outcomes for people with psychosis by delivering effective, phase-specific care for psychosis at the earliest opportunity (Marshall and Rathbone, 2011). We also aimed to focus on nursing and community care provision given that our collaboration was primarily among mental health nurses and there is a significant gap in evidence to support community nursing practice in Indonesia.

\section{Background}

Psychotic illnesses are a leading cause of burden globally (Murray et al., 2012). This burden is partly due to the relapsing nature of illness but in LMICs there are considerable treatment gaps (Patel et al., 2010, de Jesus Mari et al., 2009). In 2013, a household survey conducted by the Indonesian Ministry of Health reported the prevalence of all psychoses (of which Schizophrenia is the most common and serious) at 1.7 per 1,000 population or approximately 425,000 people. A governmental plan for delivery of mental health care was developed in 2016 titled Minimum Standard of Service, committing to the provision of basic mental health services for all. This will be a significant challenge in a nation that is $1,904,569 \mathrm{~km}^{2}$ and made up of 17,000 islands making it one of the world's largest countries (UN Data, 2017). With a population of 260 million people it is the world's $4^{\text {th }}$ most populous country and while some areas in Indonesia are counted among the most densely populated in the world, 60\% of Indonesia's population lives in rural areas (Napitulu and Saribu, 2010). Presently, up to $40 \%$ of people with psychosis do not receive any form of psychiatric treatment (Idaiani et al., 2014) and most do not receive any psychosocial interventions as these are largely unavailable and undeveloped for this population (Prasetiyawan et al., 2006). A confluence of factors contribute to the shortage of mental health services including a lack of progressive policy and governmental commitment, leadership, financing and insufficient professionally trained mental health workers (Irmansyah et al., 2009). 
The health system is mixed commercial with 14 state mental hospitals and 34+ private institutions providing varied levels of mental health care and although there is a formal mental health strategy, dedicated mental health legislation does not exist (World Health Organisation, 2011). There are 7700 beds available in state-run psychiatric hospitals which equates to 1 bed per 33,766 people (World Health Organisation, 2011). In the UK, estimates during the same period count approximately 1 bed per 2,915 people (The Kings Fund, 2015). Indonesia has an extensive primary healthcare system (puskesmas) with each sub-district having one community health centre linked to a series of smaller centres throughout the district. These centres are largely staffed by doctors, nurses and midwives implementing preventive treatment such as immunisation programmes, family planning and programmes for maternal and child malnutrition. It is estimated that approximately $16 \%$ of these facilities provide some form of mental health care (Idaiani et al., 2014) although most primary care staff including GPs do not receive any formal mental health training. In addition, the challenge of providing healthcare is immense in rural areas. As an archipelago, travel to and from health centres is problematic due to a large coastal geographical area. Studies report service-users journeys of many hours and sometimes overnight by boat and walking to attend appointments (Minas and Diatri, 2008, Kurihara and Kato, 2007).

Consequently, the burden of care for people with schizophrenia largely lies with families and communities without adequate knowledge, skills or resources to implement adequate care. Although the practice was banned in 1977, approximately 60,000 people with serious mental illness are currently in shackles (pasung), being physically restrained often in chains or wooden blocks and locked in sheds or cages. This strategy is typically implemented by families and communities and can last anywhere from a few weeks to 20+ years (Idaiani et al., 2014). Reasons families give for implementing pasung range from management of violence and aggression, lack of affordable care, treatment refusal, fear of absconsion and management of risk to self or others (Minas and Diatri, 2008). In addition, acceptance and recognition that psychosis is a treatable condition is not a widely-held belief in Indonesia and faith in the supernatural influences community decision-making in situations where psychosis emerges (Kurihara et al., 2006a). This leads to unscientific practices such as ritual healing and invoking black magic. Of the small amount of research conducted on this population, we know that routes of access to care are diverse and varied typically involving traditional healers, community leaders with much less involvement from organised care (Kurihara et al., 2006b, Marthoenis et al., 2016).

Trained mental health workers are scarce in Indonesia. There is an estimated 500+ psychiatrists working in Indonesia at last available count (Pols, 2006) and nursing professionalisation is in its infancy. The first degreebased nursing programme commenced at Universitas Indonesia in 1985 and it was not until 2005 that similar programmes became available for mental health nursing. The community is small and most academic mental health nurses at other Higher Education Institutions are alumni of Universitas Indonesia. Nonetheless, mental health workers and community nurses in particular, are a growing workforce in Indonesia with the development of community mental health models largely arising from the devastation of the 2004 tsunami in Banda Aceh (Prasetiyawan et al., 2006). This signals a timely opportunity to enhance nursing research capacity for delivering evidence-based interventions in mental health. Historically, research capacity in nursing has been underdeveloped internationally with lower levels of mentorship, leadership, organisational and structural support and low funding availability and attainment (Segrott et al., 2006, Wenke and Mickan, 2016). The growth of evidence-based practice and the transition of nursing education to university-settings are important reasons why building capacity has become important for nurses in the UK. Pragmatically, we anticipated that 
attempts to increase research capacity among nurses alone would be hindered by a lack of doctorally-prepared nurses with mental health training in both Indonesia and the UK notwithstanding that enabling multidisciplinary research is a key priority area for advancing the development of nursing research (McCance, 2007). Therefore, we aimed to support a multi-disciplinary group of early career researchers towards obtaining collaborative competitive funding with the dual benefits of enhancing capacity for researching nursing issues and increasing research leadership among nurses in both the UK and Indonesia.

By improving research capacity we aimed to enhance the ability of early career researchers to identify problems, set objectives, build sustainable infrastructure and find answers to key health problems facing service-users, families and clinicians in Indonesia (Gadsby, 2011). Increasing capacity for global health is a key target area outlined in Public Health England's Global Health Strategy 2014 -2019 and is supported by a £1.5 billion fund (Global Challenges Research Fund) made available to the research councils in 2015. We delivered an innovative intervention aimed at developing collaborative cross-cultural partnerships to increase the potential among early career researchers and nurses to obtain competitive grant funding to conduct research in early psychosis care within Indonesia.

\section{Methods}

The Intervention

The workshops were held over 4 days in Jakarta, Indonesia and facilitated by researchers and clinicians from both UK and Indonesia. We define research capacity as enhancing the ability within mental health nursing and early career researchers to undertake research (Segrott et al., 2006, McCance et al., 2007). Theoretically, the intervention was informed by the ESSENCE framework (World Health Organisation, 2016) which is an evidence-based, good practice guide for enhancing research capacity in LMICs (see Table 1). This strategy was developed by multiple health research capacity strengthening funders to coordinate and harmonise capacity building activities providing a framework for both developing and evaluating capacity (World Health Organisation, 2014, World Health Organisation, 2016). We adopted an experiential learning model to meet these principles (O'Byrne and Smith, 2011) combining small group teaching and activities with theoretical and experiential content regarding the onset and trajectory of psychotic illness, new paradigms for mental health service reform and the principles of preventive healthcare delivery. This was coupled with sustainable mentorship and supervision to enhance experiential learning. During the workshops we delivered one session on research methods (conducting systematic reviews) as a starting point for developing bids based on the Medical Research Council Framework for Developing Complex Interventions (Craig et al., 2008).

The five areas addressed themes of early psychosis care and healthcare innovation and research including;

- Early psychosis treatment principles and practice

- $\quad$ Research priorities for early psychosis care and treatment

- $\quad$ Evidence based delivery methods for training and educating the workforce

- Implementation science and translating evidence into practice

- Improving patient care through innovation 
We facilitated the development of 5 collaborative groups matching research experts with proficient researchers and novices. Principal investigators and mentors from both countries were Prof. Alison Yung (UK), Dr. Irmansyah (Indonesia), Prof. Karina Lovell (UK), Prof. Budi-Anna Keliat (Indonesia) and Dr. Laoise Renwick (UK) and were assigned to each group in addition to providing the scientific content for the workshops. We identified research priorities and ranked these in order of importance and groups were formed based on the aspiration of each participant to work in this area. Mentors were assigned on the basis of preference. Each group was guided in developing aims and objectives from research questions focused on global health strategies and local policy ensuring proposed projects were within remit for global health funding.

\section{Participants}

We primarily offered the training to mental health nurses as they represent the largest segment of mental health workers in the UK (40,000) (NHS Digital, 2017) and a growing workforce in Indonesia. We were cognisant of the need to include early career researchers with the training, skills and means to bring a research project proposal to conclusion and included a wider range of healthcare professionals with the requisite skills to lead project grants under the guidance of mentors. Consequently, we conducted our recruitment process opting for a targeted approach to ensure a higher number of appropriate applicants that fulfilled one of three criteria; early career researcher using the British Council definition, clinical research nurses, clinical research early psychosis workers. We selected the final group of attendees based on whether they fulfilled more than one of the above criteria and to ensure an adequate skill mix in terms of research and clinical knowledge to inform the research process. Participants comprised a combination of nurses, psychiatrists, social workers, psychologists and research lecturers and were located in various clinical and research settings throughout Indonesia and the UK. We actively recruited from within our networks including the Early Intervention in Psychosis Network in the North West of the UK and Mental Health Nurse Academics UK and we actively recruited from centres of research excellence in central hubs in the UK; London and Manchester. Similarly, Indonesian participants were identified through active recruitment in existing networks. In Indonesia, the workshops were over-subscribed and in the UK, there was an under-subscription (anecdotally, this seemed to be due to being limited to fitting travel around the academic calendar and some potential participants having prior commitments). Following selection we had four applicants decline involvement due to personal reasons/unable to travel due to risks associated with travel. As before, we selected participants based on the criteria above.

\section{Evaluation}

We considered the attainment of competitive grant funding as evidence of outcome attainment as this would fulfil research and development priority areas ensuring the development of skills and a focus on enhancing infrastructure and organisational capacity to support sustainable and continuous research. This is a key individual outcome indicator in the ESSENCE evaluation framework (World Health Organisation, 2016). We assessed a range of ancillary impacts and outcomes including acceptability of the workshops, daily attendance rates, informal evaluation of mentorship support plan sustainability through ongoing discussion and collation of competitive grant submissions and attainment until June 2017. On completion of the workshops, participant's views were obtained using the 'Training Acceptability Rating Scale' (Davis et al., 1989). The tool evaluates the degree of acceptability of the workshops to the participants and the perceived effectiveness using scale items. Total scoring gives a range of 6-63 with higher scores indicating greater approval of the workshops and 
methods. In addition to the overall score we present the percentage score for the two subscales (acceptability and effectiveness) by subtracting the actual score from the total possible score and multiplying by 100 . Scores in the $70-80 \%$ range are considered satisfactory and above $80 \%$ indicates training of an exceptionally high standard. The TARS is frequently used in the evaluation of mental health training and previous studies report good reliability, internal consistency and construct validity (Milne, 2010, Milne et al., 2000, Davis et al., 1989). We facilitated group feedback evaluating aspects of the workshops that were valuable and aspects that could be improved (LR \& KL co-facilitated). Each person was asked to report one like and one dislike and the responses were recorded and collated by LR. This was augmented with free-text responses from the TARS to evaluate participant's views on the content, format and delivery of the workshops. In addition, we gathered information from mentors about the progress of each group towards attaining research funding following the workshops approximately 6 months after the workshops completed. We collated these evaluation data and analysed them anonymously to protect participant's privacy. Through informal conversations with our collaborators during subsequent projects we also evaluated the unintended consequences of the workshops. Ethical approval was not required for this evaluation.

\section{Results}

There were 30 participants in total; 13 were nurses, 10 were psychiatrists, six were psychologists/psychology graduates (post-doctoral and doctoral candidates) in mental health areas and one was a social science graduate with a $\mathrm{PhD}$ in a mental health area. There were five mentors, one per group; three were nurses (KL, LR, BK) with strong research and leadership backgrounds and two were psychiatrists with strong research and leadership experience in early psychosis treatment and intervention (AY and I).

Quantitative

24 participants completed the TARS at the conclusion of the workshops. Individual item responses are presented in Table 3. The mean percentage score for satisfaction with training overall was $87 \%$ which was within the very good range for both the acceptability and the effectiveness of the workshops (Milne, 2010). We measured attendance also which was consistent across the four days of the workshops. Alongside this we were interested in whether the workshops would increase research participation as evidence by attaining competitive funding to conduct a research project. An update as at June 2017 is provided in Table 4 with the number of grants submitted, the outcome and to which research prioritisation theme they corresponded.

Qualitative

Qualitative evaluations report a range of positive outcomes for the participants including improving understanding of research, grant-getting, the importance of leadership and improving confidence to conduct research. Conducting the workshops collaboratively with researchers from both countries working together in teams was viewed as a positive aspect of the project in addition to sharing knowledge and ideas in the form of early career researcher presentations. Of particular value to participants was the opportunity for networking, obtaining skills and knowledge by learning from others and being guided through a process with clear outputs. Positive comments related also to the content of the programme and the leadership and competency of the workshops mentors. A significant number of comments related to how the experience provided renewed 
motivation and inspiration for future research. Suggestions for improvement mostly related to the format and content. To maximise the use of time we held several workshops daily and participants felt this was demanding. A suggested improvement was to allocate mentors earlier in the process and allow more time for group-work with mentors. Evaluation from mentors during the workshops debrief supported this as their focus on delivering scientific content and conducting exercises made it difficult to guide group projects and we tended to develop each project from articulating a problem statement to setting clear aims and objectives in the larger group to facilitate greater knowledge transfer among participants. A number of both Indonesian and UK participants stated their preference also for greater research methods content which we largely avoided.

\section{Discussion}

\section{Summary}

This intervention proved successful in increasing research capacity and research output of early career researchers in Indonesia and the UK. As seen from the quantitative outputs, there was demonstrable success with several research proposals being submitted, in review and funded following completion of the workshops. Some collaborative groups were maintained to a greater degree than others and newer networks developed particularly where projects required additional expertise from UK or Indonesian researchers or clinicians to maximise success. There are few examples of successful implementation of capacity-building models for nursing care in the UK (O'Byrne and Smith, 2011) and projects that are reported tend to focus on increasing capacity in terms of research utilisation among clinicians (Lode et al., 2015), among academic nurses for enhancing nurse education (Begley et al., 2014) and enhancing organisational capacity (Moore et al., 2012). Few are focused on enhancing individual and collaborative capacity in cross-cultural settings and even fewer in mental health settings.

Enhancing capacity for obtaining competitive grant bids even among UK nurse faculty and doctorally-prepared nurse researchers is difficult. Mentorship capacity is growing but still limited in the area of mental health as evidenced by the number of professorial appointees and their respective citations, although we recognise this is a narrow and limited measure of productivity and impact (Watson et al., 2017). This was also evidenced by a number of participants seeking ongoing individual mentorship from the workshop mentors. To be efficient with capacity for mentoring, furnishing early career academic nurses in the UK with opportunities to develop sustainable international collaborations while developing their leadership and research skills through this format is a worthwhile exercise. We observed that the preparedness and existing knowledge and skills of applicants is a key issue in determining some of the success as those who had experience of writing grant proposals (though not independent researchers) were more commonly submitting and acquiring competitive grant funding. These were better positioned to generate newer working collaborations among other UK researchers and cultivate and strengthen collaborations developed during the workshops emerging with stronger leadership skills. The process seemed to generate new ideas and expedite the submission of proposals simultaneously.

Generating nursing research capacity in Indonesia, our collaboration between the University of Manchester and Universitas Indonesia has strengthened and we are collaborating on enhancing publications for Indonesian nurse academics which directly challenges inequity in the publication of peer-reviewed articles to mental health 
journals originating from within LMICs (Adam et al., 2011) by facilitating submission for publication in peerreviewed English language journals with greater impact and reach further enhancing research skills of both UK and Indonesian researchers. Two UK researchers are providing scientific oversight for the Universitas Indonesia international nursing research conference which is attended by around 250 mental health nurse academics throughout South-east Asia further cementing collaborative partnerships. Enhancing clinical capacity was an unintended consequence and Indonesia's only early psychosis service at the National Centre for Mental Health was launched in response to these workshops which is an extremely favourable outcome.

\section{Interpretation}

To increase capacity among mental health nurses may seem an immense task as this is a significant challenge worldwide (McCance et al., 2007) and there are few capacity building initiatives for nurses within the international nursing community (Edwards et al., 2009). Possible explanations for why the observed outputs exceeded our expectations include strong leadership, pre-existing skill and knowledge of participants, providing a protected platform for networking and having a shared vision. A pre-existing level of research knowledge was assumed as we targeted mainly early career researchers at doctoral level and this type of intervention seemed to mobilise those with the knowledge and experience of research methods to develop coherent research projects. These types of workshops are brief and time-limited thus their influence in increasing research capacity among non-researchers may be questionable (O'Byrne and Smith, 2011) but coupled with ongoing support and mentorship from expert researchers reinforced this strategy. It is possible that factors beyond our control have impacted this endeavour such as infrastructure and support in the originating participant's organisation which we did anticipate and we contacted the candidate's line manager to ensure support where this was needed.

red vision for

Our shared vision for improved psychosis care is an integral part of this success (McCance et al., 2007) as our collaboration grew from within the IEPA Early Intervention in Mental Health and Pan-Asian Network for Early Psychosis (Larkan et al., 2016). Driving the research agenda in this way engaged enthusiastic and dedicated individuals joined by a common goal to improve care for patients. Subsequent public engagement activities by UK and Indonesian researcers have afforded an audience with officials and senior decision-makers from government offices such as the Ministry of Health and the Ministry of Research, Technology and Higher Education to influence the advancement of mental health care in Indonesia leading to support for the development of the early psychosis service at the National Centre for Mental Health. Contextually, the political advances towards universal care for mental health in Indonesia, recent lobbying by human rights groups to end pasung and the availability of global health funding sponsoring preparatory work has created an advantageous socio-political environment for continued collaboration.

\section{Limitations}

Reflecting on the conduct of the workshop and measurement of processes and outcomes, it is clear that there may have been intended and unintended consequences from the intervention and ongoing mentor support that we have not captured here. Although the intervention appeared to be discrete, we did not comprehensively evaluate the quality or quantity of the processes and outcomes from ongoing mentor support which would have illuminated partially the mechanism by which some groups were more successful than others. Nor did we evaluate entirely the characteristics of attendees which may have provided greater insight into the potential for 
success and whether the intervention should be planned by the mentors to a greater degree. We allowed attendee preference to dictate the content of the bid, the mentor and the methods chosen as we believed this was important for participant engagement. However, it could be questioned whether a more effective method would have been to artificially create groups with different abilities, knowledge, skill as variation in these i.e. expert and novice skill mix, are more consistent with effective experiential methods of enhancing research capacity.

The implications for future research in view of these limitations are that it would be beneficial to know whether greater success in achieving the outcomes were delivered by any of the processes we developed through this intervention or those beyond our control that we could either mitigate against or allow to influence our selection of potential candidates. Examples of these include the quantity of supervision and mentorship, group formation and skill mix, consistency between technical knowledge or group members and methods chosen, Englishlanguage proficiency of group members, whether the infrastructure in the originating organisation of the participant supports research and pre-existing knowledge and skill of the participant. Generating an evaluation of the wider impact of this research would be beneficial to assess the full potential for enhancing research capacity of this intervention but also to understand whether there are wider socio-political implications and changes in practice, if any.

\section{Conclusion}

As this method has been largely successful this could be implemented to improve networking and collaboration between UK academics and early career researchers in other lower and middle-income settings. The potential for applying this method to other contexts to strengthen existing partnerships among early career researchers in the UK, for example through nursing academic organisations is immense given that we developed unintended collaborations between UK researchers being mindful of the limitations above. The full potential of this innovative intervention could be realised through careful delivery and evaluation of similar in the above contexts being cognisant of both our experiences and a deeper understanding of the processes and outcomes of such an intervention.

\section{References}

AYUSO-MATEOS, J. L. 2000. Global burden from schzophrenia in the year 2000. Geneva: World Health Organisation.

BARBER, S. L. \& GERTLER, P. J. 2008. Strategies that promote high quality care in Indonesia. Health policy (Amsterdam, Netherlands), 88, 339-347.

BEGLEY, C., MCCARRON, M., HUNTLEY-MOORE, S., CONDELL, S. \& HIGGINS, A. 2014. Successful research capacity building in academic nursing and midwifery in Ireland: An exemplar. Nurse Education Today, 34, 754-760.

CRAIG, P., DIEPPE, P., MACINTYRE, S., MICHIE, S., NAZARETH, I. \& PETTICREW, M. 2008. Developing and evaluating complex interventions: the new Medical Research Council guidance. Bmj, 337, a1655. 
DAVIS, J. R., RAWANA, E. P. \& CAPPONI, D. R. 1989. Acceptability of behavioral staff management techniques. Behavioral Interventions, 4, 23-44.

DE JESUS MARI, J., RAZZOUK, D., THARA, R., EATON, J. \& THORNICROFT, G. 2009. Packages of Care for Schizophrenia in Low- and Middle-Income Countries. PLoS Medicine, 6, e1000165.

EDWARDS, N., WEBBER, J., MILL, J., KAHWA, E. \& ROELOFS, S. 2009. Building capacity for nurse-led research. Int Nurs Rev, 56, 88-94.

EVANS , J. R. 1990. Essential National Health Research. New England Journal of Medicine, 323, 913915 .

FRANZEN, S. R. P., CHANDLER, C. \& LANG, T. 2017. Health research capacity development in low and middle income countries: reality or rhetoric? A systematic meta-narrative review of the qualitative literature. BMJ Open, 7, e012332.

GADSBY, E. W. 2011. Research capacity strengthening: donor approaches to improving and assessing its impact in low- and middle-income countries. Int J Health Plann Manage, 26, 89-106.

HUMAN RIGHTS WATCH 2016. World Report 2016. New York.

IDAIANI, S., PRIHATINI, S., INDRAWATI, L. \& YUNIT, I. Psychotic and pasung in Indonesian population: A national study. The 16th Pacific Rim College of Psychiatrists Scientific Meeting, 2014 AsiaPacific Psychiatry. 1-35.

IRMANSYAH, I., PRASETYO, Y. A. \& MINAS, H. 2009. Human rights of persons with mental illness in Indonesia: more than legislation is needed. Int J Ment Health Syst, 3, 14.

JONES, S. 2016. 'Living in hell': Mentally ill people in Indonesia chained and confined. The Guardian.

KURIHARA, T. \& KATO, M. 2007. Accessibility and utilization of mental health care in Bali, Psychiatry Clin Neurosci. 2007 Apr;61(2):205.

KURIHARA, T., KATO, M., REVERGER, R. \& TIRTA, I. G. 2006a. Beliefs about causes of schizophrenia among family members: a community-based survey in Bali. Psychiatr Serv, 57, 1795-9.

KURIHARA, T., KATO, M., REVERGER, R. \& TIRTA, I. G. 2006b. Pathway to psychiatric care in Bali. Psychiatry Clin Neurosci, 60, 204-10.

LARKAN, F., UDUMA, O., LAWAL, S. A. \& VAN BAVEL, B. 2016. Developing a framework for successful research partnerships in global health. Global Health, 12, 17.

LODE, K., SÖRENSEN, E., SALMELA, S. \& SEVERINSSON, I. E. 2015. Clinical nurses' research capacity building in practice-A systematic review.

MARSHALL, M. \& RATHBONE, J. 2011. Early intervention for psychosis. Schizophr Bull, 37, 1111-4.

MARTHOENIS, M., AICHBERGER, M. C. \& SCHOULER-OCAK, M. 2016. Patterns and Determinants of Treatment Seeking among Previously Untreated Psychotic Patients in Aceh Province, Indonesia: A Qualitative Study. Scientifica, 9136079, 12.

This article is protected by copyright. All rights reserved 
MCCANCE, T. V., FITZSIMONS, D., KEENEY, S., HASSON, F. \& MCKENNA, H. P. 2007. Capacity building in nursing and midwifery research and development: an old priority with a new perspective. Journal of Advanced Nursing, 59, 57-67.

MILNE, D. 2010. Can we enhance the training of clinical supervisors? A national pilot study of an evidence-based approach. Clinical Psychology \& Psychotherapy, 17, 321-328.

MILNE, D. L., KEEGAN, D., WESTERMAN, C. \& DUDLEY, M. 2000. Systematic process and outcome evaluation of brief staff training in psychosocial interventions for severe mental illness. Journal of behavior therapy and experimental psychiatry, 31, 87-101.

MINAS, H. \& DIATRI, H. 2008. Pasung: Physical restraint and confinement of the mentally ill in the community. Int J Ment Health Syst, 2, 8.

MOORE, J., CROZIER, K. \& KITE, K. 2012. An action research approach for developing research and innovation in nursing and midwifery practice: building research capacity in one NHS foundation trust. Nurse Educ Today, 32, 39-45.

MURRAY, C. J. L., VOS, T., LOZANO, R., NAGHAVI, M., FLAXMAN, A. D., MICHAUD, C., EZZATI, M., SHIBUYA, K., SALOMON, J. A., ABDALLA, S., ABOYANS, V., ABRAHAM, J., ACKERMAN, I., AgGARWAL, R., AHN, S. Y., ALI, M. K., ALMAZROA, M. A., ALVARADO, M., ANDERSON, H. R., ANDERSON, L. M., ANDREWS, K. G., ATKINSON, C., BADDOUR, L. M., BAHALIM, A. N., BARKER-COLLO, S., BARRERO, L. H., BARTELS, D. H., BASÁÑEZ, M.-G., BAXTER, A., BELL, M. L., BENJAMIN, E. J., BENNETT, D., BERNABÉ, E., BHALLA, K., BHANDARI, B., BIKBOV, B., ABDULHAK, A. B., BIRBECK, G., BLACK, J. A., BLENCOWE, H., BLORE, J. D., BLYTH, F., BOLLIGER, I., BONAVENTURE, A., BOUFOUS, S., BOURNE, R., BOUSSINESQ, M., BRAITHWAITE, T., BRAYNE, C., BRIDGETT, L., BROOKER, S., BROOKS, P., BRUGHA, T. S., BRYAN-HANCOCK, C., BUCELLO, C., BUCHBINDER, R., BUCKLE, G., BUDKE, C. M., BURCH, M., BURNEY, P., BURSTEIN, R., CALABRIA, B., CAMPBEll, B., CANTER, C. E., CARABIN, H., CARAPETIS, J., CARMONA, L., CELLA, C., CHARLSON, F., CHEN, H., CHENG, A. T.-A., CHOU, D., CHUGH, S. S., COFFENG, L. E., COLAN, S. D., COLQUHOUN, S., COLSON, K. E., CONDON, J., CONNOR, M. D., COOPER, L. T., CORRIERE, M., CORTINOVIS, M., DE VACCARO, K. C., COUSER, W., COWIE, B. C., CRIQUI, M. H., CROSS, M., DABHADKAR, K. C., DAHIYA, M., DAHODWALA, N., DAMSERE-DERRY, J., DANAEI, G., DAVIS, A., LEO, D. D., DEGENHARDT, L., DELLAVALLE, R., DELOSSANTOS, A., DENENBERG, J., DERRETT, S., DES JARLAIS, D. C., et al. 2012. Disabilityadjusted life years (DALYs) for 291 diseases and injuries in 21 regions, 1990-2010: a systematic analysis for the Global Burden of Disease Study 2010. The Lancet, 380, 21972223.

This article is protected by copyright. All rights reserved 
NAPITULU, R. A. V. \& SARIBU, E. I. D. 2010. Is There Any Regulation to Protect People with Mental Disorders in Indonesia? (Case Study of Pasung). Indonesian Journal of International Law.

NHS DIGITAL 2017. NHS Workforce Statistics. London.

O'BYRNE, L. \& SMITH, S. 2011. Models to enhance research capacity and capability in clinical nurses: a narrative review. Journal of Clinical Nursing, 20, 1365-1371.

PATEL, V., MAJ, M., FLISHER, A. J., DE SILVA, M. J., KOSCHORKE, M. \& PRINCE, M. 2010. Reducing the treatment gap for mental disorders: a WPA survey. World Psychiatry, 9, 169-76.

POLS, H. 2006. The development of psychiatry in Indonesia: from colonial to modern times. Int Rev Psychiatry, 18, 363-70.

PRASETIYAWAN, VIORA, E., MARAMIS, A. \& KELIAT, B. A. 2006. Mental health model of care programmes after the tsunami in Aceh, Indonesia. International Review of Psychiatry, 18, 559-562.

SEGROTT, J., MCIVOR, M. \& GREEN, B. 2006. Challenges and strategies in developing nursing research capacity: A review of the literature. International Journal of Nursing Studies, 43, 637-651.

THE KINGS FUND 2015. Mental health under pressure. London: The Kings Fund.

UN DATA. 2017. United Nations Statistics [Online]. United Nations Statistics Division. [Accessed 17 02 2017].

WATSON, R., MCDONAGH, R. \& THOMPSON, D. R. 2017. h-indices: an update on the performance of professors in nursing in the UK. Journal of Advanced Nursing, 73, 999-1001.

WENKE, R. \& MICKAN, S. 2016. The role and impact of research positions within health care settings in allied health: a systematic review. BMC Health Services Research, 16, 355.

WORLD HEALTH ORGANISATION 2011. Mental Health Atlas 2011. Geneva: World Health Organisation.

WORLD HEALTH ORGANISATION 2014. Seven principles for strengthening research capacity in lowand middle-income countries: simple ideas in a complex world. Geneva.

WORLD HEALTH ORGANISATION 2016. Planning, Monitoring and Evaluation Framework for Research Capacity Strengthening. Geneva.

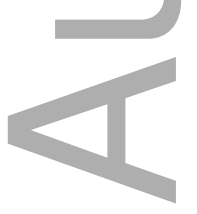

This article is protected by copyright. All rights reserved 
Table 1: Good Practice Principles Mapped onto Intervention Component

\begin{tabular}{|c|c|}
\hline ESS & ent \\
\hline $\begin{array}{l}\text { Network, } \\
\text { share expe }\end{array}$ & $\begin{array}{l}\text { UK and Indonesia early career researcher's } \\
\text { presentations, networking breaks built into the } \\
\text { workshop programme, programme presentations from } \\
\text { UK and Indonesia experts in early psychosis care }\end{array}$ \\
\hline $\begin{array}{l}\text { ontext and evaluate } \\
\text { pacity }\end{array}$ & $\begin{array}{l}\text { UK and Indonesia early career researcher's } \\
\text { presentations, presentation from Ministry of Health } \\
\text { describing health policy, embed Planning, Monitoring } \\
\text { and Evaluation Framework* into grant proposals }\end{array}$ \\
\hline nership and active & $\begin{array}{l}\text { Research prioritisation exercise to define local priorities } \\
\text { for psychosis intervention and treatment collaboratively, } \\
\text { embed partnership working and strong public } \\
\text { engagement in grant proposals using evidence-based co- } \\
\text { design, local and international mentorship }\end{array}$ \\
\hline $\begin{array}{l}\text { ng, evaluation and } \\
\text { art }\end{array}$ & $\begin{array}{l}\text { Workshop evaluation throughout, acceptability } \\
\text { evaluation, assessment of impacts following completion } \\
\text { of workshops, informal evaluation of continued mentor } \\
\text { support plan, embed Planning, Monitoring and } \\
\text { Evaluation Framework* into grant proposals }\end{array}$ \\
\hline $\begin{array}{l}\text { Establish robust research governance } \\
\text { and support structures and promote } \\
\text { effective leadership }\end{array}$ & $\begin{array}{l}\text { Ensure grant proposals where possible contain } \\
\text { interventions to enhance research support structures and } \\
\text { infrastructure within existing organisations using } \\
\text { Planning, Monitoring and Evaluation Framework* }\end{array}$ \\
\hline $\begin{array}{l}\text { Embed strong support, supervision and } \\
\text { mentorship structures }\end{array}$ & $\begin{array}{l}\text { Cross-cultural mentorship from leaders in the field of } \\
\text { nursing research and early psychosis research }\end{array}$ \\
\hline be flexible and plan & $\begin{array}{l}\text { Sustainability workshop and supervision plan } \\
\text { completing the workshops, proposal to develop centre } \\
\text { of excellence in Universitas Indonesia to develop } \\
\text { sustainable leadership and mentorship }\end{array}$ \\
\hline
\end{tabular}

Note 1* World Health Organisation, Planning, Monitoring and Evaluation Framework for Research Capacity Strengthening, 2016: Geneva. 
Table 2: Workshop Outline

\begin{tabular}{|c|c|c|c|c|}
\hline & Day 1 & Day 2 & Day 3 & Day 4 \\
\hline Session 1 & ng Ceremony & $\begin{array}{l}\text { Apply for funding; } \\
\text { know the features of a } \\
\text { successful grant } \\
\text { application } \\
\text { Groupwork } \\
\text { discussion of what } \\
\text { research questions } \\
\text { your team would like } \\
\text { to answer }\end{array}$ & $\begin{array}{l}\text { Mental healthcare in } \\
\text { Indonesia }\end{array}$ & $\begin{array}{l}\text { Groupwork } \\
\text { Group will present } \\
\text { their bid orally in } 5 \\
\text { minutes to another } \\
\text { group who will } \\
\text { form a funding } \\
\text { panel - will you } \\
\text { fund it? Why or } \\
\text { why not? }\end{array}$ \\
\hline Session 2 & $\begin{array}{l}\text { Ministry of Health, } \\
\text { Health Strategy in } \\
\text { Indonesia } \\
\text { British Council, } \\
\text { Funding Strategy }\end{array}$ & $\begin{array}{l}\text { Groupwork } \\
\text { Presentation of } \\
\text { research questions } \\
\text { from groups } \\
\text { Features of a good } \\
\text { principal investigator } \\
\text { Groupwork } \\
\text { Choose your principal } \\
\text { investigator }\end{array}$ & $\begin{array}{l}\text { Lessons learned from } \\
\text { Jakarta's pilot first } \\
\text { episode psychosis } \\
\text { clinic } 2005\end{array}$ & $\begin{array}{l}\text { Groupwork } \\
\text { Sustaining } \\
\text { networks } \\
\text { agreeing } \\
\text { framework for } \\
\text { future } \\
\text { collaboration, who } \\
\text { will submit, where } \\
\text { to and how? }\end{array}$ \\
\hline Session 3 & $\begin{array}{l}\text { Introduction to the } \\
\text { workshop; aims and } \\
\text { objectives } \\
\text { Getting to know you } \\
\text { exercise }\end{array}$ & $\begin{array}{l}\text { How does your } \\
\text { research impact } \\
\text { stakeholders and who } \\
\text { should you be asking } \\
\text { for money? } \\
\text { Groupwork } \\
\text { Developing an outline } \\
\text { bid and choosing a } \\
\text { mentor }\end{array}$ & $\begin{array}{l}\text { How to conduct a } \\
\text { systematic review } \\
\text { and meta-analysis }\end{array}$ & Closing Ceremony \\
\hline Session 4 & $\begin{array}{l}\text { Developing early } \\
\text { intervention in } \\
\text { psychosis services; } \\
\text { challenges and } \\
\text { opportunities } \\
\text { Research Prioritisation }\end{array}$ & $\begin{array}{l}\text { Early career researcher } \\
\text { presentations x } 8\end{array}$ & $\begin{array}{l}\text { Early career } \\
\text { researcher } \\
\text { presentations x } 8\end{array}$ & \\
\hline
\end{tabular}


Exercise, what are the

important questions to

be answered in

Indonesia?

\section{-}

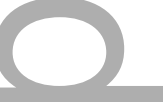

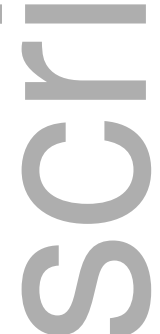

Table 3: TARS Scores Post Workshop Evaluation

\begin{tabular}{lccc}
\hline Item (Range) & Min-Max & Mean & SD \\
\hline 1. General acceptability (1-6) & $4-6$ & 5.54 & 0.59 \\
2. Effectiveness (beneficial for staff) (1-6) & $4-6$ & 5.57 & 0.59 \\
3. Appropriateness of the intervention (1-6) & $4-6$ & 5.50 & 0.59 \\
4. Consistent with good practice (1-6) & $4-6$ & 5.42 & 0.65 \\
5. Most staff would approve of this training (1-6) & $4-6$ & 5.50 & 0.59 \\
6. Did the course improve your understanding? (0-4) & $3-4$ & 3.46 & 0.51 \\
7. Did the course help develop work-related skills? (0-4) & $2-4$ & 3.29 & 0.75 \\
8. Has the course made you more confident? (0-4) & $2-4$ & 3.33 & 0.64 \\
9. Do you expect to make use of the course content in your & $3-4$ & 3.67 & 0.48 \\
workplace? (0-4) & & & \\
10. Competency of course leaders (0-4) & $3-4$ & 3.79 & 0.41 \\
11. General satisfaction (0-4) & $2-4$ & 3.71 & 0.55 \\
12. Did the course meet its objectives? (0-4) & $3-4$ & 3.52 & 0.51 \\
13. Did course leaders relate to group effectively? (0-4) & $3-4$ & 3.63 & 0.49 \\
14. Were the leaders motivating? (0-4) & $2-4$ & 3.75 & 0.53 \\
\hline
\end{tabular}




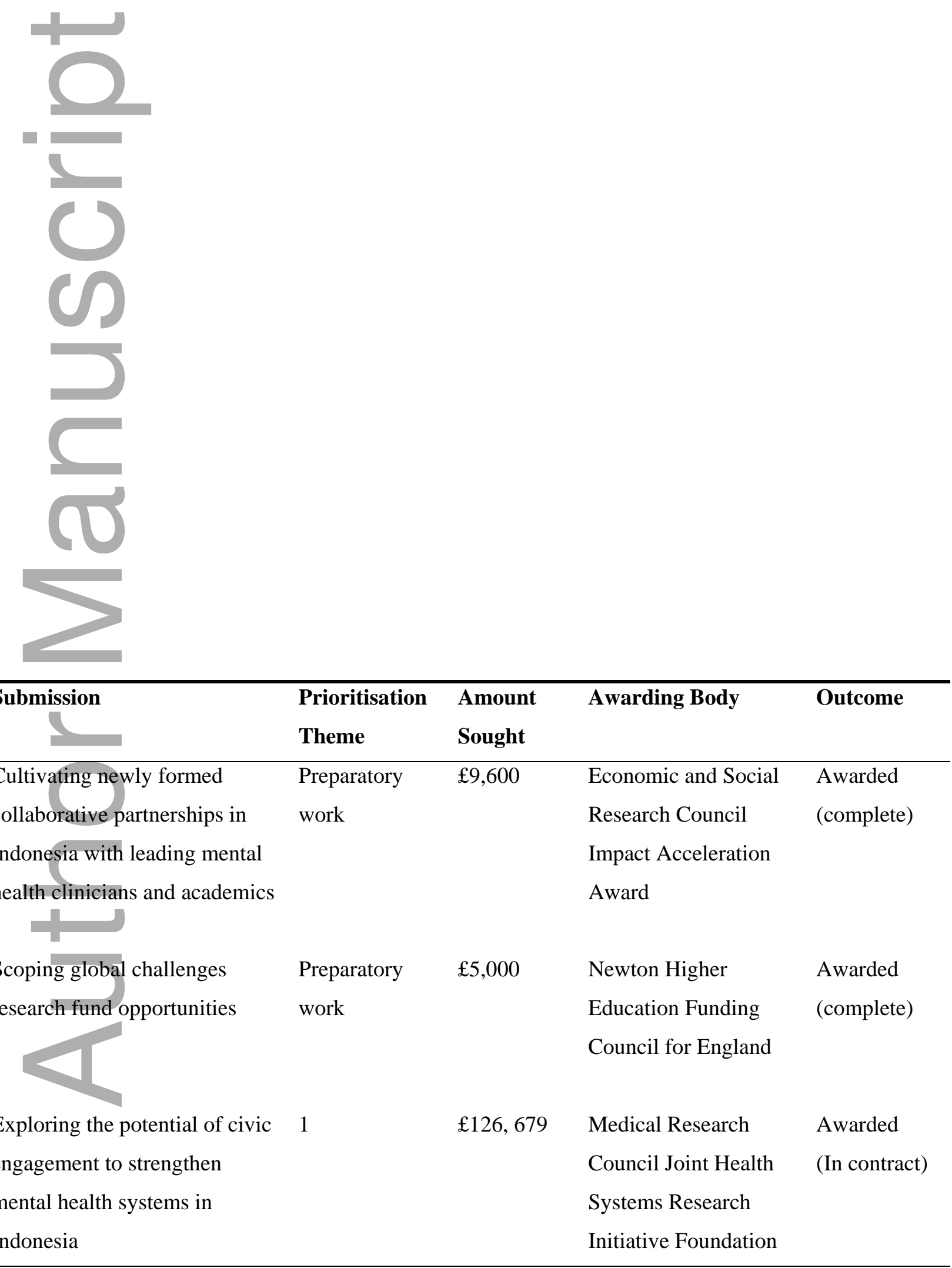




\begin{tabular}{|c|c|c|c|c|c|}
\hline April & Understanding help-seeking & 2 & $£ 127,196$ & Medical Research & Rejected \\
\hline \multirow[t]{5}{*}{2017} & and pathways to care for & & & Council Joint Health & \\
\hline & psychosis in West Java, & & & Systems Research & \\
\hline & Indones & & & Initiative Foundation & \\
\hline & & & & Grant & \\
\hline & a & & & & \\
\hline June & Improving mental health & 3 & $£ 179,107$ & Medical Research & Under \\
\hline \multirow[t]{6}{*}{2017} & literacy among young people & & & Council Adolescent & Review \\
\hline & aged 12-14 years in Jakarta, & & & Health Outline & \\
\hline & Indonesia: Co-development & & & Proposal & \\
\hline & and feasibility testing of a & & & & \\
\hline & culturally-appropriate, user- & & & & \\
\hline & centred Resource (IMPeTUs) & & & & \\
\hline June & Developing and co-creating & 1 & $£ 119,593$ & British Council & Under \\
\hline \multirow[t]{4}{*}{2017} & caregiver interventions for & & & Institutional Links & Review \\
\hline & schizophrenia in Indonesia: & & & & \\
\hline & Capacity building and & & & & \\
\hline & preparing for an Indonesian & & & & \\
\hline
\end{tabular}

\section{Table 4: Grants submitted and outcome}

Note 2: 1 = Assessing the needs of carers and families who support someone with psychosis, $2=$ Assessing the role and impact of This article is protected by copyright. All rights reserved
traditional healers in pattways to care, 3 Evatuating mental health literacy among the general population, $4=$ Generating a 


\section{University Library}

\section{- M M I N E R VA \\ A gateway to Melbourne's research publications}

Minerva Access is the Institutional Repository of The University of Melbourne

Author/s:

Renwick, L;Irmansyah,;Keliat, BA;Lovell, K;Yung, A

Title:

Implementing an innovative intervention to increase research capacity for enhancing early psychosis care in Indonesia

Date:

2017-11-01

Citation:

Renwick, L., Irmansyah, , Keliat, B. A., Lovell, K. \& Yung, A. (2017). Implementing an innovative intervention to increase research capacity for enhancing early psychosis care in Indonesia. JOURNAL OF PSYCHIATRIC AND MENTAL HEALTH NURSING, 24 (9-10), pp.671-680. https://doi.org/10.1111/jpm.12417.

Persistent Link:

http://hdl.handle.net/11343/293440 